\title{
Marketing Decision Making in the Conditions of Information Uncertainty and Business Risks on the Basis of the Stratification Metamodeling Toolkit
}

\author{
Vyacheslav Glushchevsky \\ Faculty of Economics and Management \\ Zaporizhzhia National University \\ Zaporizhzhia, Ukraine \\ gluschevsky@ukr.net \\ Kateryna Steshenko \\ Faculty of Economics and Management \\ Zaporizhzhia National University \\ Zaporizhzhia, Ukraine \\ steshik80@gmail.com
}

\author{
Viktoriia Khoroshun \\ Faculty of Economics and Management \\ Zaporizhzhia National University \\ Zaporizhzhia, Ukraine \\ vixhoroshun@gmail.com
}

\author{
Lev Feofanov \\ Faculty of Economics and Management \\ Zaporizhzhia National University \\ Zaporizhzhia, Ukraine \\ feofanovlk@gmail.com
}

\begin{abstract}
The problematic subject area studied in this article is the sphere of marketing activity and the quality management system of industrial enterprises on the example of the enterprises of the electrical engineering industry. The article addresses the following problems of marketing management of enterprises producing electrotechnical products, such as reduction of financial demand from the side of potential consumers and unplanned negative changes in products market prices. It is substantiated that marketing decisions taken by the management of the enterprise concerning the pricing of production of own manufacturing are burdened with significant business risk and are accepted in the absence of reliable operational information about the current level of indirect production and nonproductive costs in the conditions of dynamic destabilizing influences from the outside of the enterprise. It is proposed to solve outlined problems using the instrumentation of a new object-oriented approach to the synthesis of complex models of the activities of industrial enterprises - stratification metamodeling. The article describes a fragment of a stratification metamodel, which is a reference for the enterprises of the electrical engineering industry. The construction of this fragment of the stratification metamodel was carried out in three analytical contexts: conceptual modeling of marketing decision making in the conditions of information uncertainty, model decomposition of the economic problem into the multilayered hierarchy of the complex of problems and their mathematical models, information management of model knowledge and generating on this basis an effective marketing solution due to the synchronization of inputs and outputs of models of up-to-date management tasks that have created a coherent system. The system of interconnected economic and mathematical models of price, cost and profit management developed in this article is a scientific basis for the synthesis of artificial intelligence enhancement systems when adopting effective marketing decisions for the preventive elimination of the threat of price destabilization of the enterprise portfolio.
\end{abstract}

Keywords-decision making; cost management; price conflict; a set of models; stratification metamodeling

\section{INTRODUCTION}

Today, Ukraine is actively cooperating with EU member states, gradually integrating into the global European economic space. In particular, in 2015 the "Strategy for Sustainable Development of Ukraine2020" [1] was approved, which reproduces the main strategic guidelines "A European strategy for smart, sustainable and inclusive growth EUROPE -2020" [2] and is in fact a roadmap for overcoming the technological lag of Ukraine from the technological leaders in the way of development and support of domestic high-tech industries as a strategic component of the long-term process of developing an innovative economy model. Thus, the prerequisites for the development and implementation of the "Strategy for the Development of High-Tech Industries in Ukraine until 2025" were created. This Strategy is one of the main high-tech directions for Ukraine determined by high-tech industrial engineering, including branch of production of electric equipment. This type of economic activity, that is, "Production of electrical equipment", against the backdrop of the entire industry of Ukraine, despite the crisis state of the modern economy, shows clear positive prospects for development [1]. Achievement of the purpose of this Strategy for specific domestic industrial enterprises is possible due to the formation of favorable marketing conditions through the implementation of organizational and economic instruments and scientific innovations, the creation of effective management mechanisms.

The product range of the electrotechnical industrial enterprise is electric motors, transformers of various types and complete sets, various electro-distributing equipment, control equipment and others like mentioned. The main consumers of this electrical product are electrical networks, power plants, industrial enterprises, agricultural facilities, and others like that. The regulation of the relationship between the electrotechnical company and the business partners is in the field of marketing activity and quality management of products, namely: 
- The basis of marketing management is the fundamental principles of international standards ISO [3], in particular the following: the customer establishes requirements for the level of product quality; effective managerial decisions are made solely on the basis of the analysis of factual data and information; the enterprise and its business partners are interdependent - mutually beneficial relations increase the ability of both parties to create values effectively.

- Sectoral specificity of marketing management electrical products are knowledge intensive and hightech, mostly narrow-directed, has a unique configuration and specification in accordance with the requirements of customers, is made exclusively "under the order" after contracting with the customer.

- The purpose of marketing management - to maximize profits by expanding and optimizing the structure of the portfolio of enterprise orders (PEO): PEO is a set of current concluded or potential orders, which are documented (a contract has been concluded); the current PEO is the basis for the formation of a production plan for the enterprise.

- The most topical problems of marketing management is reduction of solvent demand from potential customers and unplanned negative changes in market prices for electrical products.

The decisive influence on the efficiency of the marketing management of the electrotechnical enterprise is the decision on the pricing of products of own production, especially when the planned price, which is the basis of calculations of the system of indicators of economic efficiency of the enterprise, does not meet the customer's expectations (exceeds the acceptable price for the contract price) and there is a threat of failure contractual processes (the so-called "price conflict") due to the impossibility of reaching a price compromise on such "problem" orders. Such marketing decisions are burdened with significant risk because they are accepted in the conditions of information uncertainty about possible actions from the side of potential business partners.

The effectiveness of marketing management of an electrotechnical enterprise is inextricably linked with accounting and cost management. The enterprise records the costs of production and sales of products in accordance with the current "Accounting Standard" Expenditures", using the Absorption Costing (AC) [4] full cost method. General production and overhead non-production costs are allocated for the output of the $\mathrm{i}$ - type in proportion to a certain distribution base. As a rule, the following distribution bases of indirect costs are used: wages of the main production workers for labor-intensive products, the cost of direct material costs for material-intensive products, the volume of production, the sum of all direct costs, etc. Such a procedure is formal and substantially burdened by subjectivity in the allocation of indirect costs for the range of PEO, since:

- Distribution bases are set by the enterprise independently with their accounting policies.

- The extent to which these distribution bases are "successfully" selected depends on which part of the total costs will be offset by the price of one or another product.

- There is a risk of distorting the results of the calculation of the full unit cost of production, which adversely affects the planned prices (there is a risk that prices will be unreasonably overestimated) and, as a result, can lead to lower competitiveness on target product markets and a reduction in the economic profitability of the enterprise.

The main reasons for this problem are:

- The imperfection of the methodology for calculating indirect costs, the cost of which is a component of the full cost of assortment types of products of the electrical engineering company.

- Weak consistency of the current methodology of accounting and calculation of costs for the production and sale of products with recognized world-wide management accounting techniques, in particular, with Direct Cost accounting (DC).

- Underdevelopment of the mechanisms of the appropriate agreement of the planned price with the contractual price for the product range of the planned PEO.

- Absence of flexible management communications between different organizational units of the enterprise involved in substantiating the possibilities, cost-effectiveness and marketing expediency of providing discounts to business partners in accordance with the basic principle of ISO "Customer Orientation" (Target Costing Concept), etc.

The generalization of the listed aspects of this problem for Ukrainian machine-building enterprises, in particular for electrotechnical enterprises, stimulates the search for hidden reserves to eliminate the highlighted threat of a "price conflict" between producers and consumers of products, namely:

- Initiates solving the task of reconciling the planned price with the contract price for the "problem" order by way of reducing the planned price to a "compromise" level by reducing the planned profit rate in order to find an acceptable "price compromise".

- If this task is not effective, even if the profit margin for the products of this "problem" order is artificially reduced to $0 \%$, that is, the full cost per unit of such product, which is calculated by the AC-method, is not covered by a "compromise" price, but this price is considered economically unprofitable, the task of determining the zone of maneuvering with target (indirect) costs is initiated with the aim of their target redistribution among other orders included in the planned PEO (if they do not exceed the level of their economic profitability).

- Under these conditions, the task of efficient distribution and / or task of the target redistribution of total indirect costs for the assortment of planned PEO, which should be solved in a coordinated 
manner on the basis of methods of economicmathematical modeling, is relevant.

The systemic leveling of a number of objective and subjective problems of the system of planning (modeling), which is traditional for Ukrainian enterprises, and the management of the price and expenses consumed in the process of production and sale of products, requires the development of new methodological approaches to the decision-making on eliminating potential "price conflicts" at the dynamic management of the structure of the PEO. In our opinion, the perspective direction in the modeling of such complex systems of industrial enterprises management is the synthesis of artificial systems of intelligence enhancement through the systematic coordination of a complex of economic and mathematical models of management of costs, prices, profits, etc. This will increase the informative and manageable pricing process; obtain at the expense of this lost profit and competitive advantages, increase the efficiency and adaptability of marketing decisions taken on this basis in the absence of reliable information on the actual cost of industrial products. The development of scientific research in this direction is the subject of this article.

\section{MethodologicAl ReviEw: THEORY, Hypothesis}

The results obtained by the authors, which are highlighted in the article, are based on the system of conditions, principles and tools of the theory of adaptive management of systems, the theory of hierarchical systems and system analysis, the architectural methodology of creating business models of enterprises, economic and mathematical modeling, etc. [5-8] that are used for mathematical support and formalization of marketing decision making processes based on a new object-oriented approach to the synthesis of complex business models stratification metamodeling. Methodology of stratification metamodeling was developed and substantiated by one of the authors in a number of scientific works on this subject and summarized briefly in [9]. This methodology develops the principles of multimodality and stratification in the development of theoretical and methodological approaches and mathematical tools for the reflection, analysis, synthesis and coordination of asynchronous models of dynamically interacting subsystems of the enterprise control system to raise the quality of the rationale and cost-effectiveness of managerial decisions and reduce business risks (to get more about author's work in this area, we recommend referring to the author's profile, in particular, in Google Scholar).

The methodology of stratification metamodeling allows us to implement a multidimensional formalized representation of the enterprise in the context of the interaction of its management subsystems in the form of asynchronous complex models of activity from the point of view of different analytic perspectives (the number, type, and content of these analytical angles is not principled, although experts in the field of stratification of economic systems and metamodeling technology offer to use simultaneously 3-5 different analytical measurements (stratification representations or strata ) [10-14]).

The article describes only a fragment constructed by one of the authors of the stratification metamodel of the electrotechnical enterprise (described in detail in [9]), which covers three of the five developed stratification representations of the enterprise (these strata are synchronized with each other at the level of models of their heterogeneous objects-subsystems), namely:

- Semantic representation - ensures the conceptualization of the subject area, which is the marketing sphere of the activity of the electrotechnical enterprise, including production planning, pricing and financial analysis of performance.

- Algorithmic representation - provides multilayered decomposition of the economic problem through the hierarchy of tasks and their mathematical models (balance, optimization, predictive, regression models, etc.).

- Information representation - establishes dynamic interconnections between models of actualized tasks at the level of their equivalent parameters; provides a synthesis of the target model complex for solving the current economic problem.

\section{RESULTS AND DISCUSSION}

\section{A. Conceptual (semantic) modeling}

Conceptualization of the domain is carried out with the help of the methodology of the method of conceptual (semantic) modeling, with the use of which a conceptual model is constructed in the form (1):

$$
C M=\left\langle\left\{C N C_{f}\right\}, R\left(\left\{C N C_{f_{1}}\right\},\left\{C N C_{f_{2}}\right\}\right)\right\rangle, f=\overline{1, F},
$$

where $\left\{\mathrm{CNC}_{\mathrm{f}}\right\},\left\{\mathrm{R}\left(\mathrm{CNC}_{\mathrm{fl}} ; \mathrm{CNC}_{\mathrm{f} 2}\right)\right\}$ - the set of conceptions and semantic links (meaningful and logical), respectively, between pairs of concepts of conceptual model CM; $f, f_{1}, f_{2}-$ identifiers of unique concepts.

Conceptual model CM - "Modeling of marketing decisions in conditions of information uncertainty" is schematically presented in Fig. 1.

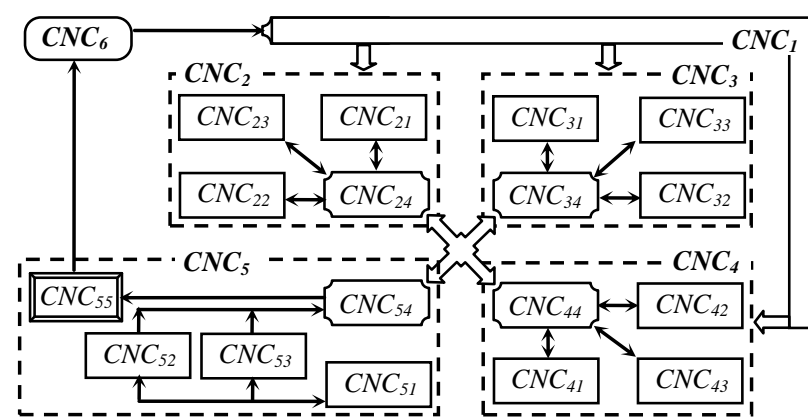

Fig. 1. Conceptual scheme of marketing decisions modeling in conditions of information uncertainty

This conceptual model:

- Implements a systematic approach to solving the problem of managing the marketing policy of an enterprise in conditions of information uncertainty and risk.

- Allows you to highlight a set of interrelated managerial tasks, the solution of which is based on the system of marketing management. 
- There is a theoretical basis for the development of economics and mathematical tools (a set of models, algorithms, mechanisms) in relation to the substantiation of effective marketing decisions.

$\mathrm{CNC}_{\mathrm{g}}$ Concepts - are named, independently identified structural constructions of the subject area that contain information about it (knowledge) and are its basic epistemological units, define implicit rules that reproduce at the abstract level (speculative) the structure, properties and specifics of the functioning of a real object (electrotechnical enterprise) $[15,16]$.

The list and the essential content of the concepts we have constructed, which form the conceptual model on fig. 1, is presented and summarized as follows:

$\mathrm{CNC}_{1}$ - Information management: collecting internal and external input data, consolidating them with model data.

$\mathrm{CNC}_{2}$ - Modeling of the production program: modeling of the planned needs of the enterprise in all types of resources, taking into account the range of planned PEO.

$\mathrm{CNC}_{21}$ - Model production plan: optimization of the schedule of loading of production lines of the enterprise, taking into account the nomenclature of PEO according to concluded agreements with business partners.

$\mathrm{CNC}_{22}$ - Modeling a sales plan: modeling the forecasted demand for relevant segments of the commodity market to formulate a plan and timetable for the shipment of finished products to business partners in accordance with the concluded agreements.

$\mathrm{CNC}_{23}$ - Production program budget: aggregate the value of all production resources for the production of the range of products included in the planned PEO.

$\mathrm{CNC}_{24}$ - Modeling of financial results: scenario modeling of financial results of an enterprise: estimation of efficiency of production factors use.

$\mathrm{CNC}_{3}$ - Cost modeling for assortment range of the enterprise: simulation of the target cost of production from assortment set of PEO based on Target Costing concept.

$\mathrm{CNC}_{31}, \mathrm{CNC}_{32}-$ Modeling the cost of production by full and direct costs, respectively: forms a set of economic and mathematical models for the calculation and distribution of production and overhead costs by the method of full and direct costs respectively (AC and DC methods).

$\mathrm{CNC}_{33}$ - Economic analysis: factor economic analysis and preventive control over the costs of production and sales of products from planned PEO.

$\mathrm{CNC}_{34}$ - Modeling margin income: a system of models of margin economic and mathematical analysis of profits of the enterprise; Model experiments on the step-by-step calculation of the sum of cover systems.

$\mathrm{CNC}_{4}$ - Modeling and forecasting of market conjuncture: collection and consolidation of model (including forecast) and actual (including retrospective) data on the results of marketing research of a competitive commodity market or its individual segments.
$\mathrm{CNC}_{41}, \mathrm{CNC}_{42}$ - Demand and supply modeling, respectively: modeling of the expected behavior of consumers and competitors according to target product market segments; reflexive evaluation of competitors' response to their own marketing policy.

$\mathrm{CNC}_{43}$ - Price monitoring: Information retrieval of various data on the prices of products of the planned PEO with the identification of major competitors, substitutes and other related and auxiliary goods.

$\mathrm{CNC}_{44}$ - Design of price-demand supply-demand elasticity functions: marketing analysis of target product market segments with the use of detected stochastic dependencies of forecasted demand and supply from the expected market price for planned products (using Balanced Scorecard (BSC) and target performance indicators - Key Performance Indicator (KPI), justification of the ranges of competitive prices for their own products and the economic feasibility of using the system of discounts).

$\mathrm{CNC}_{5}-$ Cost management for the production and sales of planned PEO products: scenario simulation (What Is Needed For and What - If Analysis) to identify and set boundaries of the price range (the upper limit of the price is determined by market demand, the lower price limit must compensate for the production costs and sales of products).

$\mathrm{CNC}_{51}-$ Bases for the distribution of indirect costs for the product range for planned PEO: a system of models for the distribution of indirect costs of the enterprise (generic and overhead) for individual products from planned PEO using alternative distribution bases.

$\mathrm{CNC}_{52}, \mathrm{CNC}_{53}-$ Management of the distribution of indirect, respectively, production and non-productive costs: simulation of the cost of the total production and nonproduction (overhead) costs of the enterprise, assigned to the product range from the planned PEO, based on a variable system of distribution bases.

$\mathrm{CNC}_{54}$ - Optimization of the "cost-price-profit" relationship: simulation of the effective price range, taking into account the dynamics of model (planned) costs for the production and sales of products included in the planned PEO, and the size of the model demand.

$\mathrm{CNC}_{55}$ - Generation of managerial decisions: adaptive DSS-mechanisms (DSS - Decision Support System); effective pricing modeling; modeling the target cost of production; simulation of target reduction and / or redistribution of indirect costs.

$\mathrm{CNC}_{6}$ - External environment: simulation of the effect of external destabilizing factors on business processes of the enterprise.

\section{B. Modeling system}

On the basis of the conceptual model CM - "Marketing management of production enterprise costs", taking into account the essence of its concepts, a complex of urgent tasks is identified and structural-functional, logical and informational links between them are established. For the part of these tasks a system of economic and mathematical models is constructed, which is set up on the complex solution of a number of economic problems in the field of marketing management of the enterprise. 
1. Theoretical hypotheses concerning the construction of a system of models:

- There is no method of accounting for costs that would provide the calculation of the only "correct", "true", "exact" value of the costs of production and sales of products.

- The quality of operational information about the level of costs in the conditions of dynamic changes is determined by the method of their attribution to one or another type of product: the simulation of the dependence of the cost of indirect costs from the combined choice of reference bases of their distribution on the products of the $i$-type is carried out by the method of constructing a system of models of multiple regression, which are under construction on the basis of retrospective statistics.

- Structural decomposition of the full cost index for a "problem" order is carried out by the way of integration of the two concepts of cost accounting $\mathrm{AC}$ and DC methods.

- The total value of all direct production costs and all indirect costs is planned for the next calendar year, taking into account the structure of planned PEO and is considered to be well-known.

- Formation of the company's marketing policy involves modeling a promising price based on the total cost price of the products included in the planned PEO, taking into account the results of modeling the "target" level of costs based on the concept of Target Costing.

2. Designation in models (2)-(7): $i, g$ - product identifiers and indirect costs $(g=1$ - are generic; $g=2-$ administrative; $g=3$ - for sales; $g=4$ - other); $i_{1} \in I$ identifier of "problem" order; $n_{i}, \bar{p}_{i}, p_{i_{1}}^{*}-$ norm of profit, planned and "compromise" prices per unit of products of the type «i $\rangle$ and $\left\langle i_{1}\right\rangle$ respectively; $V_{i}^{P \Gamma \Pi}-$ the physical volume (plan) of sold products of $i$-type; $\operatorname{Sob}_{i}^{P \Gamma I}, \operatorname{Sob}_{i}, S_{\text {Sob }}^{\prime}{ }^{-}$ specific costs, respectively, all direct, full plan and after target redistribution; $\overline{\operatorname{Sob}}_{i_{1}}-$ the full unit cost of the product to order $\left\langle i_{1}\right\rangle$ (the marginal cost of all direct costs, calculated by the DC-method); $\operatorname{Sob}_{i}{ }^{g},\left(\operatorname{Sob}_{i}{ }^{g}\right)^{*}-$ the specific cost of the total indirect costs for the $i$-th products of the type " $g$ " and all types; $Z_{\Sigma}^{g}, Z_{\Sigma i}{ }^{g}-$ the total cost of indirect costs of type " $g$ " together for the planned PEO and for the particular $i$-type of products, respectively; $\varepsilon_{\Sigma_{i}}^{g}=f\left(\vec{a} ; X_{l i}\right)$ - empirical estimates of $Z_{\Sigma i}{ }^{g}$ values (in the general case, are models of multiple regression: $X_{l i}$ - regressors $-l$ reference bases of distribution of indirect costs for products of the $i$-type); $\Delta Z_{\Sigma}, \Delta Z_{\Sigma i}$ - total indirect costs, respectively, for all products of the $i$-type; the same designations, but with the lower index $\left\langle i_{1}\right\rangle$ mean the same, only for the order $\left\langle i_{1}\right\rangle ; k_{i g}$ - weight coefficients (system of distribution bases) - share of total expenditures of $g$-type in the cost of production of the $i$-type; $k_{i g}{ }^{\prime}, i \neq i_{1},-$ weighting factors (system of redistribution bases); $k_{i g}{ }^{m i n}$, $\left(k_{i g}\right)^{\min }$ - limit values for the $i$-base of distribution and redistribution.

3. A fragment of the constructed system of models is represented by the expressions (2)-(7).
Model of the problem of distribution of indirect costs for the assortment of scheduled PEO. Model (2)-(4) reproduces the process of demolishing all total costs for individual products or individual orders included in the planned PEO to determine the effective distribution system $\left\{k_{i g}\right\}$ (variables model).

$$
\begin{aligned}
& \sum_{g=1}^{4}\left[\sum_{i=1}^{I}\left(\xi_{\Sigma_{i}}^{g}-k_{i g} Z_{\Sigma}^{g}\right)^{2}\right] \rightarrow \min \\
& \left\{\begin{array}{l}
\sum_{g=1}^{4}\left(k_{i g} Z_{\Sigma}^{g}\right) \leq \Delta Z_{\Sigma_{i}}, \quad i=\overline{1, I} ; \\
\sum_{i=1}^{I} k_{i g}=1, g=\overline{1,4} ; \\
k_{i g}^{\min } \leq k_{i g} \leq 1, i=\overline{1, I}, g=\overline{1,4} .
\end{array}\right. \\
& {\left[\begin{array}{l}
{\left[Z_{\Sigma}^{g}\right] \frac{k_{i g}}{\longrightarrow}\left\{Z_{\Sigma_{i}}^{g}\right\}, i=\overline{1, I}, g=\overline{1,4} ;} \\
Z_{\Sigma}^{g}=\sum_{i=1}^{I} Z_{\Sigma_{i}}^{g} ; \\
\epsilon_{\Sigma_{i}}^{g}=f\left(\vec{a} ; Z_{\Sigma_{i}}^{g}\right) ; \\
\Delta Z_{\Sigma_{i}}=V_{i}^{P \Gamma I I} \cdot\left(\operatorname{Sob}_{i}^{g}\right)^{*} ; \\
\left(\operatorname{Sob}_{i}^{g}\right)^{*}=\sum_{g=1}^{4} \operatorname{Sob}_{i}^{g}=\left(\bar{p}_{i}-n_{i}\right)-\operatorname{Sob}_{i}^{P \Gamma I I} .
\end{array}\right.}
\end{aligned}
$$

Model of task of target redistribution of total indirect costs for assortment set of planned PEO. On the basis of model (5)-(7) the plane of maneuvering is constructed with the value of the full cost price of the unit of the product of the "problem" order with the aim of its adjustment by redistributing the value of "target" indirect costs (amount of overexpenditure) to all but the "problem", the order of the planned PEO (if not exceeding their economic profitability) method of determining the rational system of coefficients $\left\{k_{i g}{ }^{\prime}\right\}$ (variables models).

$$
\begin{aligned}
& \Delta Z_{\Sigma_{i_{1}}}-\sum_{i=1 ; i \neq i_{1}}^{I} \sum_{g=1}^{4}\left(k_{i_{g}}^{\prime} \cdot \Delta Z_{\Sigma_{i_{1}}}^{g}\right) \rightarrow \min \\
& \left(\sum_{g=1}^{4}\left(k_{i g}^{\prime} \cdot \Delta Z_{\Sigma_{i_{1}}}^{g}\right) \leq V_{i}^{P \Gamma I} \cdot\left(\bar{p}_{i}-\operatorname{Sob}_{i}\right), \quad i=\overline{1, I}, i \neq i_{1} ;\right.
\end{aligned}
$$

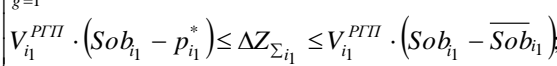

$$
\begin{aligned}
& \sum_{i=1 ; i \neq i_{1}}^{I} k_{i g}^{\prime}=1, \quad g=\overline{1,4} \text {; } \\
& \left(k_{i g}^{\prime}\right)^{\min } \leq k_{i g}^{\prime} \leq 1, i=\overline{1, I}, i \neq i_{1}, g=\overline{1,4} . \\
& {\left[\left[\sum_{g=1}^{4} \Delta Z_{\Sigma_{i_{1}}}^{g}\right] \stackrel{k_{i g}^{\prime}}{\longrightarrow}\left\{\Delta Z_{\Sigma_{i}}^{g}\right\}_{\substack{i=1,1, l \\
i \neq i \mid}}^{\substack{g=\overline{1}, i=1}}\right.} \\
& \operatorname{Sob}_{i}^{\prime}\left(k_{i g}^{\prime}\right)=\left(1 / V_{i}^{P \Gamma I}\right) \sum_{g=1}^{4}\left(k_{i g}^{\prime} \Delta Z_{\Sigma_{i_{1}}}^{g}\right)+\operatorname{Sob}_{i} ; \\
& \Delta Z_{\Sigma_{i_{1}}}=\sum_{g=1}^{4} \Delta Z_{\Sigma_{i_{1}}}^{g}=V_{i_{1}}^{P \Gamma I} \cdot\left(\operatorname{Sob}_{i_{1}}^{g}\right)^{*} \text {; } \\
& \left(\operatorname{Sob}_{i_{1}}^{g}\right)^{*}=\sum_{g=1}^{4} \operatorname{Sob}_{i_{1}}^{g}=p_{i_{1}}^{*}-\operatorname{Sob}_{i_{1}}^{P \Gamma I}
\end{aligned}
$$




\section{Methods, results of analysis and modeling}

In general terms, the function of the goals and limitations of the models (2)-(4) and (5)-(7) can be linear or nonlinear. Depending on their mathematical form, one should choose a method of solving. We presented the target function of the model (2)-(4) as the square of the difference between empirical and theoretical data. Therefore, this model relates to the problems of quadratic programming: the target function is quadratic, discontinuous; all restrictions are linear and form a convex set of permissible solutions; the method of solving - the method of Lagrange multipliers with the Kuhn-Tucker conditions. The system of constraints of the model (5)-(7) introduces an exogenous parameter $p_{i_{1}}^{*}$.

Therefore, this model relates to the tasks of parametric linear programming and is solved by the appropriate effective methods.

The modeling of the dependence of the cost of indirect costs on the choice of reference bases of their distribution on the products of the i- type is based on the built-up system of models of multiple regression: the regressors are $X_{1 i}$ - the main wages of production workers, $X_{2 i}$ - direct material costs, $X_{3 i}$ - all direct production costs, $X_{4 i}$ - market prices; check of regressants for multicollinearity carried out by the Farrar-Glauber test; an estimation of unknown parameters of regression is executed on the basis of correlation-regression analysis. Prospects for using the constructed system of models: if the problem (5)-(7) has a valid solving $\left\{k_{i g}{ }^{\prime}\right\}$ (the only or a certain set of them), then the problem (2)-(4) agreed with it is solved, taking into account the updated data on the values of $Z_{\Sigma i}{ }^{g} \quad(i=1, \ldots, I, \quad g=1,2,3,4)$, which are calculated using the system of the corresponding models of cost management, marginal factor analysis of profit, etc.

\section{CONCLUSION}

The modeling of the planned PEO is based on the results of the marketing research of the target segments of the markets for the sale of electrotechnical products, which are processed, systematized and transmitted for the preparation and approval by the management of the enterprise and the customer of the project of the commercial proposal. In case of dissatisfaction of the customer with separate positions of the commercial proposal (in particular, "price conflict", financial conditions, etc.), the technical and technological and financial and economic analysis of these positions of the commercial proposal for the search for hidden reserves to eliminate the highlighted threats is carried out. A rational decision (refusal to order or providing a discount to the customer) is approved on the basis of the results of a scenario analysis of the structural stability of the planned PEO with the involvement of a system of logical and mathematical conditions for evaluating its profitability and using the target model of management of prices, costs and profits. This fact allows companies to conduct a dynamic evaluation of profitability in the marketing management process and to analyze the sensitivity of model PEO to be resistant to destabilizing disturbances. Modeling knowledge management based on the stratification metamodelling toolkit demonstrates the possibility of dynamically extending the structure of the model complex due to the discovery of hidden logic-structural links between equivalent model parameters. Further research should concentrate on a wide range of economic problems arising from changes in business models of the enterprise, which simultaneously transform into a source of new opportunities.

\section{ACKNOWLEDGEMENTS}

This study was supported by the Ukrainian Ministry of Education and Science, Project No. 0116U002596, «Development of Methodology and Toolkit of Modeling Risks in the System of Economic Security».

\section{REFERENCES}

[1] V. Heiets, Eds, Innovative Ukraine 2020: National Report. Kyiv, UA: NAS, 2015.

[2] European Commission. (2010, March). Europe 2020 : A strategy for smart, sustainable and inclusive growth. Brussels. COM(2010) 2020 final. [Online]. Available: http://ec.europa.eu/eu2020/pdf/. Accessed on: July 10, 2019.

[3] International Organization for Standardization. (2000, Dec.). ISO 9001:2000 - Quality management systems - Requirements. [Online]. Available: https://www.iso.org/standard/21823.html. Accessed on: July 10, 2019.

[4] Ministry of Finance of Ukraine. (1999, Dec. 31). Order №318, Regulation (Standard) of Accounting 16 "Cost". [Online]. Available: https://zakon.help/law/318/

[5] D. Macko, General systems theory approach to multilevel systems. Systems Res. Center Rep. SRC 106-A-67-44, 1967.

[6] M. Mesarovic, D. Macko, and Y. Takahara, Structuring of multilevel systems. Dusseldorf, DEU: Proc. IFAC Symp. Multivariable Systems, 1968.

[7] T. Koehler, and S. Alter, "Using Enterprise Architecture to Attain Full Benefits from Corporate Big Data while Refurbishing Legacy Work Systems", in Proceedings of CBI 2016 Industrial Track. [Online]. Available: http://ceur-ws.org/Vol-1753/paper1.pdf. Accessed on: July 10, 2019.

[8] International Organization for Standardization. ISO 15704:2000 Industrial Automation Systems - Requirements For Enterprisereference Architectures and Methodologies. [Online]. Available: https://www.iso.org/ standard/28777.html. Accessed on: July 10, 2019.

[9] V. Vitlinskyi, and V. Glushchevsky, "Consideration of risk and safety in stratification metamodeling system" in Proc. SHS Web of Conf. M3E2, Odessa, 2019, 65, 08002. doi:10.1051/shsconf/20196508002.

[10] J. P. van Gigch, System Design Modeling and Metamodeling. New York, USA: Plenum Press, 1991

[11] J. Lapalme, A. Gerber, A. Van der Merwe, J. Zachman, M. De Vries, and K. Hinkelmann, "Exploring the future of Enterprise Architecture: A Zachman Perspective". [Online]. Available: https://repository.up.ac.za/bitstream/handle/2263/55648/Lapalme_Ex ploring_2016.pdf?sequence=1. Accessed on: July 10, 2019.

[12] N. Lychkina, and Ju. Morozova, "Stratifikacija kak osnova inzhenerii tehnologij komp'juternoj podderzhki prinjatija gosudarstvennyh reshenij v pensionnoj sfere" ("Stratification as the basis of computer technology engineering support for making state decisions in the pension sphere"), Business Informatics, no. 2 (20), pp. 20-28, 2012.

[13] V. V. Nechaev, Introduction to the Systems Metamodeling Theory. Moscow, RU: Informatsyiologia, 1997.

[14] J. Zachman, "John Zachman's Concise Definition of the Zachman Framework". Zachman International, Inc, 2008. [Online]. Available: https://www.zachman.com/about-the-zachman-framework. Accessed on: July 10, 2019.

[15] Ye.V. Burov, Kontseptualne modeliuvannia intelektualnykh prohramnykh system (Conceptual Modeling of Intelligent Software Systems). Monograph. Lviv, UA: Vyd. Lviv. Politekh., 2012.

[16] H. Kangassalo, "Approaches to the Active Conceptual Modeling of Learning", in ACM-L 2006. Lecture Notes in Computer Science, P.P. Chen and L.Y. Wong, Eds. Berlin, Heidelberg, DEU: Springer, 2007, vol. 4512, pp. 168-193. doi:10.1007/978-3-540-77503-4_14. 